American Scientist (January-February 1996), "the gender gap has all but disappeared". In a study of men and women in physics, maths and engineering, Sonnert and Holton found there was a significant gap between academic ranks attained in the United States. The gap was particularly pronounced in younger scientists.

Although the situation is slowly becoming more equitable (women account for 15 per cent of PhDs in the United States compared with 3 per cent 30 years ago), the disparity between the numbers of women and men succeeding in physics persists.

In the July 1997 issue of Physics and Society, for example, Jolanta Lagowski and Janis McKenna found that 18 per cent of those receiving a bachelor's degree in physics in Canada were women; 13 per cent of all $\mathrm{PhDs}$ in physics went to women and 5 per cent of faculty staff were women. Only 2 per cent of tenured physics faculty members were women. The authors collected responses from 40 institutions, and of these 80 per cent had one or no women faculty members in their physics departments. Nearly half of the 40 institutions had no women faculty members in physics. The figures, say Lagowski and McKenna, are similar to those in the United States but worse than in Europe. In France, Italy and Turkey, 23 per cent of physics faculty members in 1991 were women.

Although Lagowski and McKenna do not attempt to explain the differences they found, D. Elizabeth Pugel in an article in the same issue explores the stages from birth in the development of a physicist. A sociological approach highlights four factors in the nurturing of a scientific outlook: parental behaviour, toy selection, and the wider relationships of the child and the adolescent.

For nearly 30 years, researchers have noted that most people allow infant boys greater freedom than girls to crawl around exploring their surroundings. Stereotyping follows, which can, of course, be reinforced by the toys that parents select. Pugel points out that the selection of dolls that purportedly enhances social skills is not a bad thing in today's large collaborative teams of physicists. The problem occurs when these social skills are perceived as drawbacks by others.

Some school teachers, says Pugel, are still of a generation in which a science education for girls was not particularly emphasized. Even if they do teach science to young children, women teachers may be intimidated by science and provide poor role models. Few, if any, women physicists have the public status of Einstein or Oppenheimer.

Nevertheless, young girls do become physicists, even though the data show them trapped firmly beneath the glass ceiling. In the July 1996 issue of Physics and Society, Howard Georgi, former chairman of the physics department at Harvard University, wrote of senior faculty meetings at Harvard:

\title{
Equality not taken for granted
}

The response across the world could be measured on the Richter scale after the revelation that the Swedish medical research council (MRC) exercised prejudice in its allocation of research fellowships (A. Wold and C. Wennerås, Nature 387, 341-343; 1997).

Six months later, the implications are still being discussed in the newspapers and on radio and TV. But has anything really changed? Most definitely yes, say Agnes Wold and Christine Wennerås, the authors of the Nature Commentary. The MRC has finally accepted that it had been acting unfairly, and has changed its procedures. And some research councils in other countries - for example, the United Kingdom (see Breen, G. Nature 389, 326; 1997) - are checking their own procedures.

Wold and Wennerås had to fight hard to convince Sweden's MRC that it had a problem. They began their investigations into its peerreview system two years ago, but were hampered by its lack of cooperation. The research council's belief in its system of meritocracy was unshakeable, says Wold. She and Wennerås had to get court orders to force the MRC to make documents available. Their analysis of the peerreviewers' reports showed that in 1995 (the only year they were able to study), a woman applying for a postdoctoral fellowship had to be two-and-a-half times more productive than a man to rate the same scientific competence scores by referees. The analysis revealed that connections to any of the reviewers, independent of gender, helped bump up competence scores.

Wold believes that the MRC was genuinely unaware of the prejudices it was harbouring. Women reviewers were not significantly fairer than men, she says, when it came to estimating the skills of their own sex.

After the Nature article was published, the MRC began its own studies into possible prejudice in its allocation of project money, which it says it intends to publish. Although it found no evidence that the scientific competence of women had been misjudged, it did find that it allocated smaller grants to women than to men with identical competence ratings. Jan Nilsson, vice-secretary of the MRC, says that he and the MRC's subcommittees which had advised on grant distribution were shocked by the revelation. "It came as a complete surprise. We had a fair system for grading scientists but transforming the grading to size of grant proved - unexpectedly - to be less rigid". The MRC has already corrected this tendency, he says, and the size of grants allocated this autumn were based only on competency scores. This proves, says a delighted Wold, that there is no truth in the adage that "things can only change slowly because they have been like this for hundreds of years".

Wold is intolerant of attempts to personalize the issue of discrimination. Discrimination is simply about prejudice, she says, and has nothing to do with family status, self-esteem, or any other fantasized female attribute that some claim contributes to women being taken less seriously. "It is a purely statistical problem and making it personal serves only to lower standards of discussion." Wold has now raised the discussion to a level that has brought tangible results.

Alison Abbott
"I was appalled by the old-boys-club atmosphere that oozed from these gatherings, and I began to feel that an invasion of dragons was needed to shake up the country club."

Georgi believes that women often seem outwardly less sure of themselves than men. Initially, he found that this diffidence made it difficult for him to communicate as effectively with women as with male students. He also consistently discovered that women graduate students were more talented than was suggested by their entry examinations.

This point, argues Georgi, suggests the need for an affirmative-action programme - an unfashionable view both in academic institutions and in the law courts (see Nature 376, 288; $1995 \& \mathbf{3 8 4}, 97 ; 1996)$. Thus if there is reason to suspect that woman or 'minority' students are better than their applications suggest and an interview reveals them to be as capable as the best white male students, then there is a case for affirmative action. Of those women that do gain faculty positions,
Georgi argues, "We are still shoehorning women into a programme that works well for men but not for women and then trying to deal with the problems that arise." Georgi concludes: "You have to be an optimist and keep trying... Things are getting better, but always more slowly than we would like." Helen Gavaghan is a freelance science and technology writer based in Hebden Bridge, UK.

\section{Careers and recruitment in Nature}

Earlier Careers and Recruitment features include:

\section{Immunology (13 February issue) \\ Plant science (22 May issue) \\ Bioinformatics (25 September issue)}

Nature welcomes comments from readers, in the form of information about recruitment programmes, readers' experiences, or their reactions to the articles published. Comments should be sent in the first instance to:

Maxine Clarke at m.clarke@nature.com. 